\title{
ATIVIDADE HEMAGLUTINANTE EM SEMENTES DE DIOCLEA ROSTRATA BENTH.
}

\author{
Grangeiro, T.B ${ }^{2}$ \\ De Oliveira, J.T.A. ${ }^{1}$ \\ Moreira, R.A.' \\ Cavada, B.S.'
}

\begin{abstract}
RESUMO - Sementes de Dioclea rostrata Benth. Têm uma lectina que é melhor extraída em tampão acetato de sódio a pH 4,0 e é seletivamente adsorvida em $\mathrm{Se}$ phadex G-50, apresentando um alto título de hemaglutinação contra eritrócitos de coelho. A lectina também aglutina inespecificamente hemácias de carneiro e humanas. A atividade hemaglutinante é inibida por glicose, frutose, manose e alfa-metil-D-manosídeo, sendo os dois últimos os mais potentes inibidores. A lectina é uma metaloproteína, uma vez que a atividade hemaglutinamente desaparece na presença de EDTA.
\end{abstract}

Palavras-chave: Lectina, Dioclea rostrata

ABSTRACT - Seeds of Dioclea rostrata Benth. Have a lectin which is best extracted with $\mathrm{Na}$-acetate buffer at $\mathrm{pH} 4.0$ and that is selectively adsorbed in a Sephadex G-50 matrix, yielding a protein fraction of high hemagg lutinating titre against rabbit erythrocytes. It also agglutinates sheep, and human cells inespecifically. Its hemagglutinating activity is inhibited by glucose fructose, mannose and O-methyl-D-mannopyranoside the latter two being the most active inhibitors. The lectin seems to be a metaloprotein since the hemagglutinating activity is lost in the presence of EDTA.

Key words: Lectin, Dioclea rostrata

\section{Introdução}

A capacidade de extratos de sementes de certas plantas de aglutinar eritrócitos foi primeiramente detectada por Stillmark em 1888 (Etzler, 1985). Alguns anos depois, descobriu-se que tal propriedade era devido a presença de

1 - Universidade Federal do Ceará, Centro de Ciências, Departamento de Bioquímica e Biologia Molecular, Caixa Postal 1065 - 60.001 - Fortaleza - CE

2 - Bolsista de iniciação científica do CNPq. 
proteínas, chamadas de lectinas, que apresentavam ligação específica e reversível a carboidratos de superfícies celulares (Sharon \& Lis, 1972). Ainda que alguns fosfolipídeos (Tsivion \& Sharon, 1981) e também taninos (Makela, 1957) sejam capazes de aglutinar hemácias, a aglutinação mediada por lectinas pode ser inibida por açúcares.

Apesar de sua ampla distribuição na natureza, as lectinas de plantas têm sido as mais estudadas, principalmente aquelas presentes em sementes de plantas Euphorbiaceae e Leguminoseae. Nesta última família, a presença de lectinas têm sido detecada em mais de 600 espécies e variedades (Liener, 1976), constatando-se uma grande homologia entre as lectinas já isoladas e caracterizadas, principalmente entre lectinas pertencentes à mesma tribo (Etzler, 1985).

No presente trabalho são apresentados alguns dados sobre a atividade hemaglutinante presente em sementes de Dioclea rostrata Benth., leguminosa papilionoidea pertencente a tribo Diocleae, na qual a presença de lectinas tem sido bastante estudada (Moreira \& Cavada, 1984; Moreira et al., 1983; De Oliveira et al., 1990).

\section{Material e métodos}

\section{Material Vegetal}

Sementes de Dioclea rostrata Benth. foram coletadas no município de Barbalha, Estado do Ceará, Brasil.

\section{Concentração de Proteínas Solúveis}

A concentração de proteínas solúveis nos extratos foi determinada pelo método de Bradford (1976), usando-se albumina sérica bovina como padrão, enquanto que nos eluatos cromatográficos, foi usada a absorvância a $280 \mathrm{~nm}$.

\section{Ensaio de Atividade Hemaglutinante}

A atividade hemaglutinante nos extratos foi determinada segundo o método descrito por Moreira \& Perrone (1977), usando-se suspensões de hemácias humanas (A, B e O) e de vários animais a $2 \%$. A atividade hemaglutinante específica foi expressa como unidade de hemaglutinação (U.H.) $\mathrm{mg}^{-1}$. Uma U.H. foi estabelecida como a concentração de proteínas por ml no último tubo que apresentou hemaglutinação visível.

Extração a Diferentes pHs.

A farinha de sementes desprovidas do tegumento foi colocada para ex- 
trair, numa relação $1: 15(\mathrm{p} / \mathrm{v})$, com diferentes soluções-tampão $(\mathrm{T}$. Glicina $0,1 \mathrm{M} p H=2,6, \mathrm{~T}$. Acetato de Sódio $0,2 \mathrm{M} \mathrm{pH}=4,0, \mathrm{~T}$. Fosfato de Sódio $0,5 \mathrm{M} \mathrm{pH}=6,0$ e $\mathrm{pH}=8,0$ e T. Borato de Sódio $0,5 \mathrm{M} \mathrm{pH}=10,0$, todos contendo $\mathrm{NaCl} 0,15 \mathrm{M}$ ). Após 3 horas de contato com agitação, a suspensão foi centrifugada a $15.000 \mathrm{~g}$ por 20 minutos, a $4^{\circ} \mathrm{C}$. Os extratos totais assim obtidos foram usados para a determinação de proteínas solúveis e atividade hemaglutinante.

Inibição da Atividade Hemaglutinante por Açúcares.

As soluções de açúcares, $(0,25 \mathrm{ml})$ na concentração inicial de $1 \mathrm{M}$, foram diluídas em série, adicionando-se posteriormente extrato total $(0,25 \mathrm{ml})$ numa diluição correspondente ao dobro da unidade hemaglutinante (2xU.H.), previamente determinada. Para cada açúcar usado, foi determinada a menor concentração $(\mathrm{mM})$ capaz de inibir uma U.H.

Cromatografia de Afinidade em Coluna de Sephadex G-50.

A coluna de Sephadex G-50 $(1,3 \times 19 \mathrm{~cm})$ foi equilibrada com $\mathrm{NaCl}$ $0,15 \mathrm{M}$ com $\mathrm{Ca}^{2+}$ e $\mathrm{Mn}^{2+} 5 \mathrm{mM}$. A amostra foi aplicada à coluna e eluída inicialmente com a solução de equilíbrio até a eluição de todo o material não retido, sendo então eluída com tampão glicina $0,1 \mathrm{M}$ pH 2,6 contendo $\mathrm{NaCl}$ $0,15 \mathrm{M}$ ou solução de glicose $0,1 \mathrm{M}$.

\section{Efeito de EDTA na Atividade Hemaglutinante.}

O efeito do EDTA na atividade hemaglutinante foi determinado diluindo-se a fração PIII $(2 \mathrm{mg} / \mathrm{ml})$, obtida por cromatografia de afinidade em coluna de Sephadex G-50, em soluções de ED̄TA a diferentes concentrações e medindo-se posteriormente a atividade hemaglutinante residual.

\section{Resultados e discussão}

A figura $\mathrm{n}$ - 1 mostra os resultados obtidos quando a farinha de D. rostrata foi submetida a extrações a diferentes pHs. Observou-se que em pHs ácidos, do ponto de vista de atividade específica (UH/mg P), a lectina foi melhor extraída, sobressaindo-se a extração a pH 4,0. Estes resultados estão de acordo com aqueles obtidos para as lectinas de Dioclea grandiflora (Moreira et al, 1983), Dioclea guianensis var. lasiophylla (Vasconcelos, 1990) e Cratylia floribunda (De Oliveira et al, 1990). 
O extrato total a pH 4,0 foi testado com relação a especificidade sangüínea. Este extrato foi capaz de aglutinar diferentes hemácias tanto do sistema humano $\mathrm{A}, \mathrm{B}$ e $\mathrm{O}$ como as de coelho, aglutinou fracamente as hemácias de carneiro e mostrou-se incapaz de aglutinar as hemácias de boi, cabra e galinha (Tabela 1). Por outro lado, as hemácias que foram melhor aglutinadas foram as de coelho, utilizadas nas determinações posteriores.

A atividade hemaglutinante do extrato a $\mathrm{pH} 4,0$, foi medida por diferentes açúcares, tendo a glicose, manose, frutose e seus derivados sido os mais potentes inibidores (Tabela 2). Esses resultados confirmam os já obtidos para lectinas de outras espécies da tribo Diocleae (Moreira \& Cavada, 1984; De Oliveira et al, 1990; Vasconcelos, 1990).

$\mathrm{O}$ extrato total a $\mathrm{pH} 4,0$ foi cromatografado em uma coluna de Sephadex G-50 (Figura 2) e a fração ativa retida (PIII, lectina) foi, então, eluída com o tampão de equilíbrio contendo glicose $0,1 \mathrm{M}$. A fração ativa PIII, quando tratada com EDTA $25 \mathrm{mM}$ é capaz de ocasionar a perda em $75 \%$ da atividade hemaglutinante. Estes resultados sugerem que esta lectina é dependente de metais pesados para apresentar atividade hemaglutinante.

\section{Referências bibliográficas}

BRADFORD, M.M. 1976. A rapid and sensitive method for the quantitation of microgram quantities of protein-dye binding. Anal. Biochem. 72:248-254.

ETZLER, M.E. 1985. Plant Lectins Molecular and Biological Aspects Ann. Rev. Plant. Physiol. 36:209-34.

LIENER, I.E. 1976. Phytohemagglutinins (phytolectins). Ann. Rev. Physiol. 27:291-319.

MAKELA, O. 1957. Studies in hemaglutinins of leguminosae seeds. Ann. Med. Exp. Biol. Fenn. 35 (Suppl. 11):1-133.

MOREIRA, R.A. \& J.C. PERRONE, 1977. Purification and partial Characterization of a lectin from Phaseolus vulgaris. Plant. Phisiol. 59:783-787.

MOREIRA, R.A.; A.C.H. BARROS; J.C. STEWART \& A. PUSZTAI, 1983. Isolation and characterization of a lectin from the seeds of Dioclea grandiflora (Mart.). Planta. 158:63-69.

MOREIRA, R.A. \& B.S. CAVADA, 1984. Isolation, characterization and behavior of the lectin from Canavalia brasiliensis Mart. seeds during germination. Biologia Plantarum. 26(2):113-120.

OLIVEIRA, J.T.A. 1990. Isolation and partial characterization of a lectin from Cratylia floribunda Mart. seeds. Rev. Bras. Bot. (aceito para publicação).

SHARON, N. \& H. LIS, 1972. Lectins: Cell - Agglutinating and sugarspecific proteins. Science, 177.(4053):951-959. 
TSIVION, Y. \& N. SHARON, 1981. Lipid mediated hemagglutination and its relevance to lectin - mediated agglutination. Biochem. Bioplys. Acta. 642:336-44.

VASCONCELOS, I. M. 1990. Lectina de Dioclea guianensis Duke. var. lasiophylla. Dissertação de Mestrado Departamento de Bioquímica e Biologia Molecular da UFC. 107pp.

TABELA 1 - Especificidade por Hemácias do Extrato Total de Dioclea rostrata Benth.

\begin{tabular}{lcc}
\hline Hemácias (2\%) & Título (U.H./ml) \\
\hline Coelho & 512 \\
Boi & - \\
Cabra & - \\
Carneiro & 1,5 \\
Galinha & & - \\
Humanas & A & 96 \\
& B & 36 \\
& O & 192 \\
\hline
\end{tabular}

TABELA 2 - Inibição da Atividade Hemaglutinante do Extrato Total de·Dioclea rostrata por Açúcares.

\begin{tabular}{lc}
\hline Açúcar (100mM) & $\begin{array}{r}\text { Concentração Mínim } \\
1 \text { UH (mM) }\end{array}$ \\
\hline L (+) Arabinose & $\mathrm{NI}$ \\
D (-) Frutose & 12,5 \\
D (+) Fucose & $\mathrm{NI}$ \\
D (+) Glicose & 100 \\
D (+) Galactose & $\mathrm{NI}$ \\
Alfa-Metil-D-Glicosídeo & 12,5 \\
D (+) Glicosamina & 6,25 \\
D (+) Manose & $\mathrm{NI}$ \\
D - Manosamina & 3,12 \\
Alfa-Metil-D-Manosídeo & $\mathrm{NI}$ \\
Raffinose & $\mathrm{NI}$ \\
L (+) Rhamnose & $\mathrm{NI}$ \\
D (+) Xilose &
\end{tabular}

* NI - Não Inibiu 


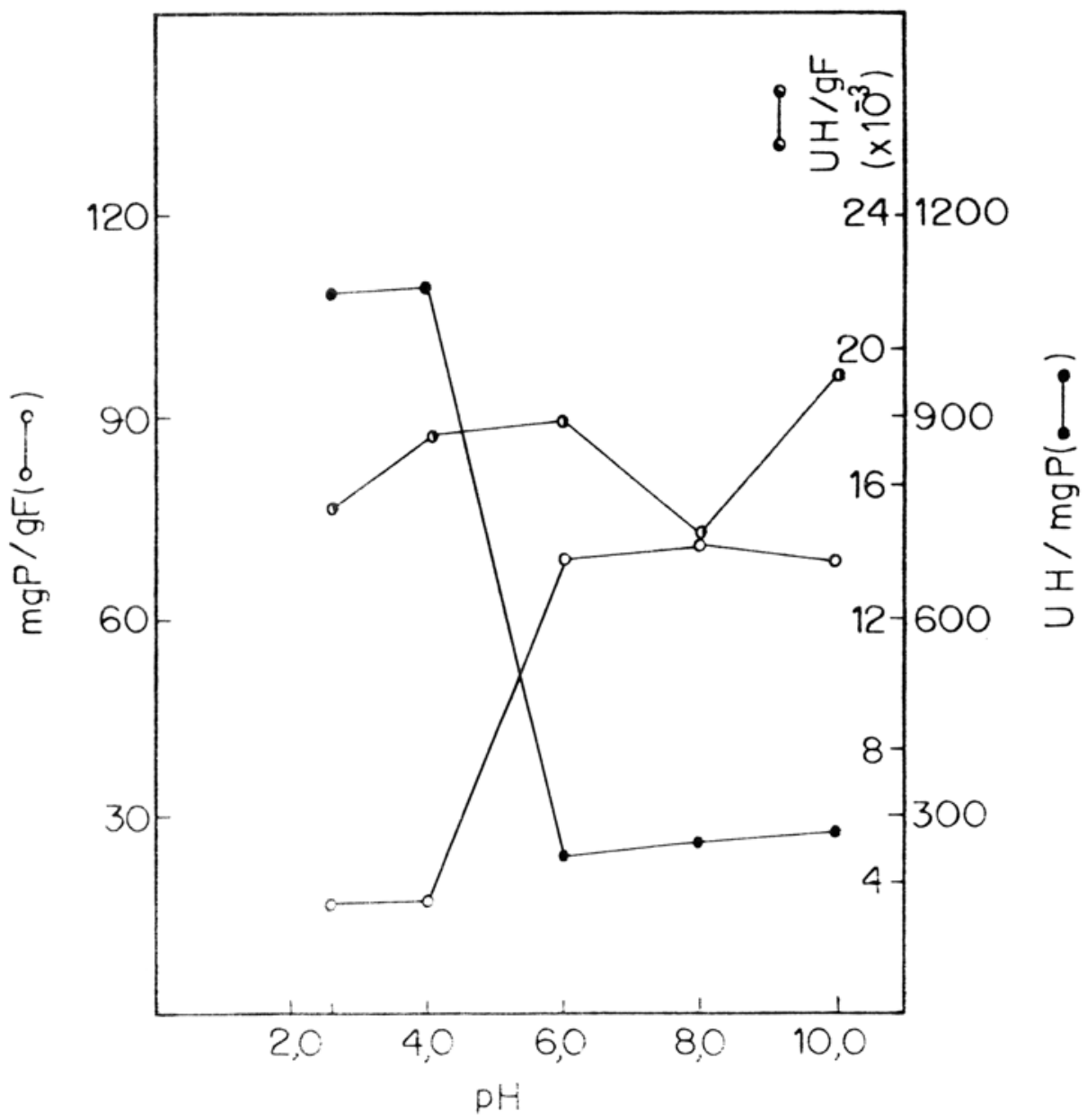

Figura 1. Extração de proteínas e atividade hemaglutinante de sementes de Dioclea rostrata a diferentes pHs. 


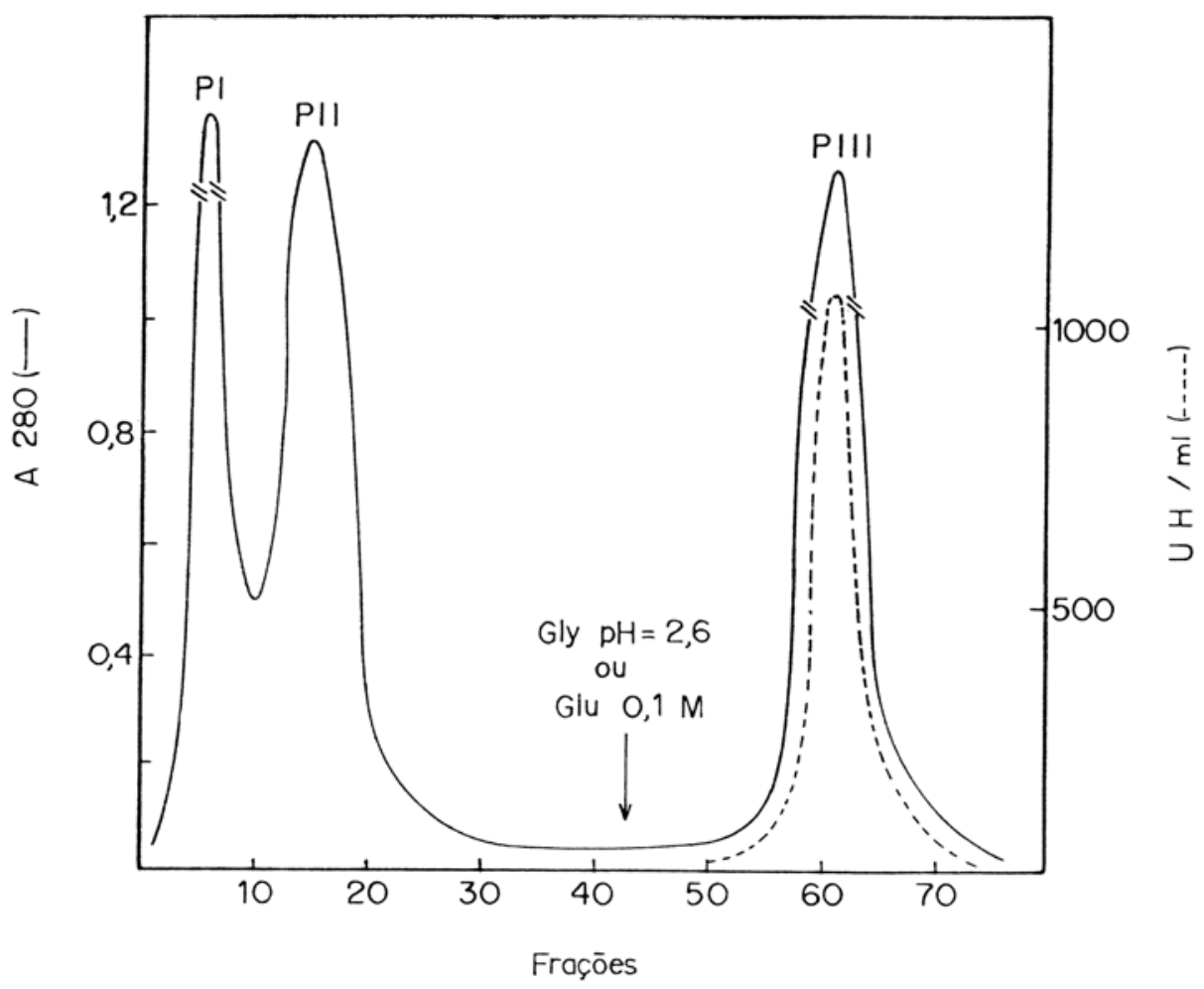

Figura 2. Cromatografia de afinidade em coluna de Sephadex G-50 do extrato total de Dioclea rostrata. Gly pH 2,6: Tampão glicina $0,1 \mathrm{M}, \mathrm{pH} 2,6$ contendo $\mathrm{NaCl} 0,15 \mathrm{M}$; Glu 0,1M: $\mathrm{NaCl} 0,15 \mathrm{M}$ contendo glucose 0,1M. ( $\left.-\mathrm{A}_{280}-\longrightarrow, \mathrm{U} . \mathrm{H} . / \mathrm{ml}\right)$. 


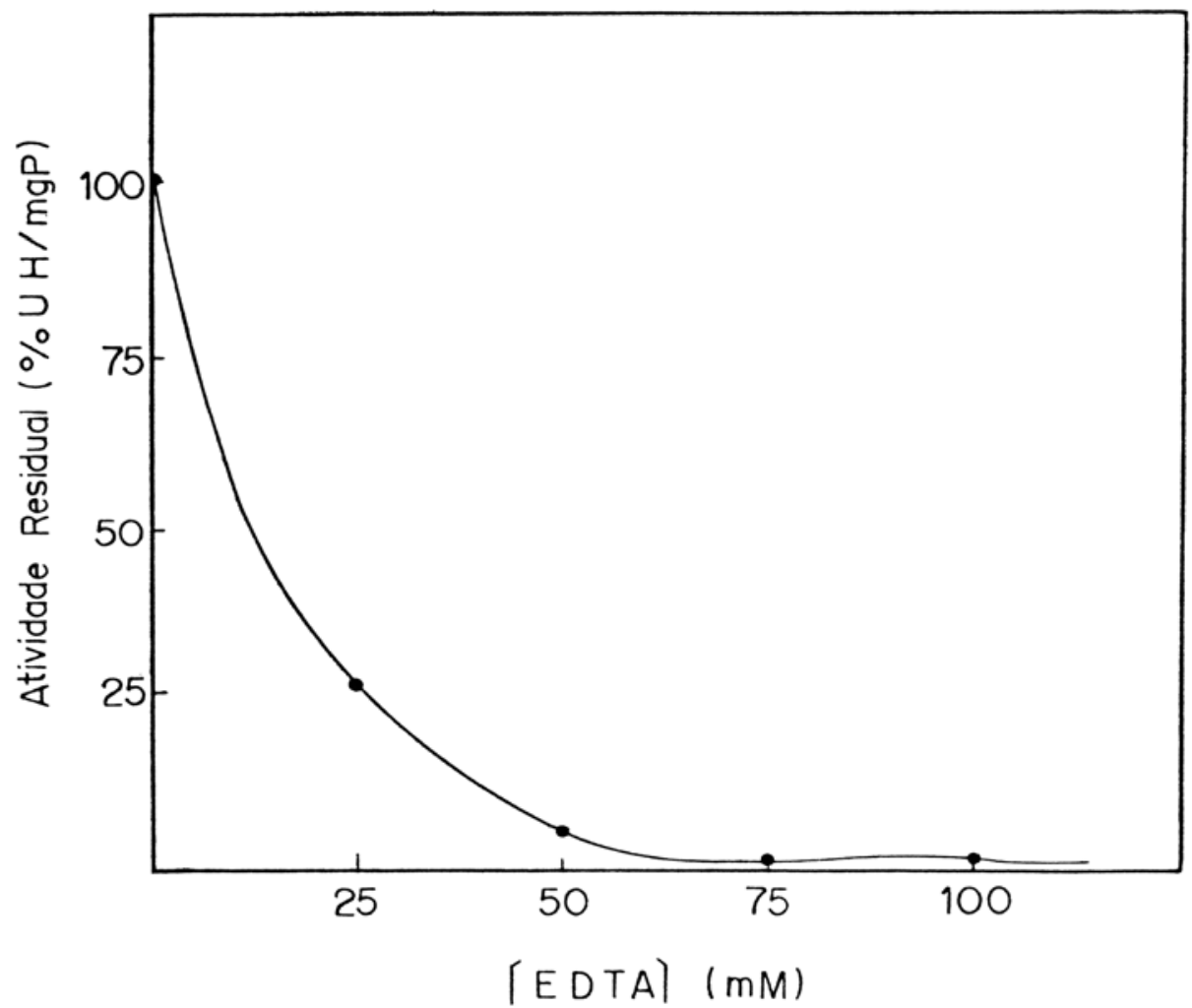

Figura 3. Efeito do EDTA na atividade hemaglutinante do PIII (lectina) de Dioclea rostrata 